Lowry and W. H. George spoke of the difficulties of teaching sound to music students, and the latter spoke also of the new M.Sc. course in the University of London, while Mr. S. R. Humby amplified previous speakers' comments on the teaching of wave motion to sixth-form schoolboys. At the conclusion of the discussion, experiments suitable for demonstrations were inspected.

\section{PHYSIOLOGY OF THE HOST- PARASITE RELATIONSHIP IN FUNGI AND BACTERIA}

$\mathrm{T}$

HE annual plant-pathological meeting of the British Mycological Society, which was held on October 17 in the Physics Lecture Theatre of Birkbeck College, London, took the form of a symposium on the physiological relationship of host plant and parasite. Nine papers were read dealing with various aspects of this wide problem.

Prof. W. Brown (Imperial College of Science and Technology, London), who introduced the discussion, dealt primarily with the type of facultative parasite which is relatively non-specialized and which characteristically brings about a distinct rotting and killing of the host tissue. This is probably the simplest of all types and the one most open to investigation, as the effects arising are localized to the neighbourhood of the parasite and can, to a large extent, be reproduced in vitro. It is logical, therefore, to begin by attempting to elucidate the mechanism of the more generalized parasites and to proceed from there to the more specialized types, as illustrated by the obligate but also by many facultative parasites.

Events which take place before the parasite has penetrated the outer wall of the host and the act of penetration itself are of considerable interest and practical importance, and the physiology of these stages could be further clarified. It is, however, when entry has taken place that the most interesting relationships develop. The tissue-destroying agents are metabolites excreted by the parasites, and, though it is not safe to ignore any of these, chief attention has been paid to pectolytic enzymes and organic acids. With some fungi, such as Botrytis cinerea, pectin-dissolving enzymes appear to be the sole agents. The study of this parasite and of others which act similarly, for example, Pythium spp., Bacterium aroidece, has thus become largely enzymological, with special reference to the conditions which govern enzyme secretion, and to the detailed differences in behaviour (such as selective action on various cell walls and constituents of cell walls, relation to $p \mathrm{H}$. and to various retarding and inhibiting agents, etc.) which are shown by the pectolytic enzyme systems of various parasites and saprophytes.

The part played by contact stimulation (thigmotropism) in the physiology of obligate parasites was discussed by Dr. S. Dickinson (Cambridge). It has been shown that the latter (rusts, powdery and downy mildews) respond to a contact stimulus by division of their nuclei, such stimulation being given on contact with stomatal guard cells, cuticle of epidermis, mesophyll wall and perhaps even outer layer of the protoplast. Thigmotropism is therefore a primary factor in obligate parasitism, a view which accords with recent American work in this field. It is suggested that this particular response to contact stimulation is the chief distinguishing characteristic between obligate and facultative parasites, and that in other ways, for example nutrition, they do not materially differ.

Dr. S. E. Jacobs and Mr. A. H. Dadd (Imperial College of Science and Technology, London), dealing with the leafy-gall organism (Corynebacterium fascians) and its behaviour on a wide range of host plants, showed that diffusible antibiotic substances are present in seeds of some of these host species. An inverse relation was discovered between percentage of seedling infection and the degree of inhibition of the bacterium brought about by exudates from seed. The inhibitory substance, when present, could be removed by soaking the seeds, but this treatment did not lead to increased infection; it had the reverse effect, possibly because of simultaneous removal of diffusible nutrients. Extracts of crushed seeds, especially after being allowed to undergo a certain amount of bacterial decomposition, stimulated growth of the parasite and increased the pathogenicity of all pathogenic strains, but failed to stimulate nonpathogenic strains to attack the host. These effects were likewise obtained by use of various chemical substances.

Mr. J. E. Crosse (East Malling Research Station) outlined the annual cycle of the bacteria] canker disease of cherry caused by Pseudomonas morsprunorum, an over-wintering canker phase on the bark alternating with an over-summering leaf-spot phase. Infections of the bark take place in the autumn and mainly through the scar-wounds which arise at leaf-fall. Experiments with concentrated inocula gave a much higher percentage infection of a resistant as compared with a susceptible variety than was normally encountered in the field. This disparity was traced to the fact that in the autumn the parasite was more abundant on the leaves of the susceptible than of the resistant variety. As the infective bacteria are washed down by rain, the concentration of inoculum in the infection drops is likely to be higher in the susceptible variety.

A series of inoculation experiments, carried out with a range of concentrations of inoculum and at four dates during the leaf-fall period, showed clearly that the concentration of inoculum necessary to give 50 per cent infection was higher with the resistant variety. Resistance to canker under field conditions was thus a compound of two factors, a lower prevalence of the parasite on the leaf surface and a higher threshold concentration of inoculum required for infection. As a result, the conditions necessary for successful invasion were less often realized at ports of entry on the resistant variety. Infectivity of leaf scars had also been shown to vary with the date at which inoculum was applied; but the precise relationship had not yet been worked out.

Dr. P. S. Nutman (Rothamsted Experimental Station) discussed the interaction between leguminous plants, in particular clover, and strains of the noduleforming organism. 'Effective' or symbiotic strains produced a limited number of nodules which were large and which fixed nitrogen; 'ineffective' or parasitic strains gave nodules in abundance, but these remained small because of early degeneration of their growing-points and they did not fix nitrogen. Incompatibility between the clover plant and $a$ bacterial strain which was normally effective was also shown in certain nutritive states of the former, and the same appearances resulted as with an 
ineffective strain. Both types of nodules arose at points which were potentially the initials of side roots. Experiments on nodule and root-tip excision had furnished evidence of an inhibitory activity centred in the growing-points of root and nodule, so that in effective symbiosis the first-formed nodules tended to suppress the development of nearby nodules and lateral initials, whereas ephemeral ineffective nodules had no such effect.

Developments in fungal enzymology, most of which had relation to industrial fermentations and food technology, were reviewed by Dr. R. K. S. Wood (Imperial College of Science and Technology, London). In contrast, the enzymological aspects of parasitism had been incompletely studied. No enzyme capable of attacking cutin was known, and it was not clear whether the death of cells which followed the enzymatic maceration of cell wall was due to the enzyme or to a specific toxic substance. The various types of pectolytic enzymes, he said, are as yet not clearly defined because of incomplete knowledge of the vurious kinds of pectic materials present in plants. Cellulolytic and proteolytic enzymes will probably also have to be taken into account.

Dr. F. T. Last (Rothamsted Experimental Station) described the behaviour of the mildew fungus, Erysiphe graminis, in relation to growth of the cereal plant as modified by application of nitrogenous fertilizer. The effect of the fertilizer was to increase the relative growth-rate of the host to a maximum, after which it fell, a series of changes which was paralleled by the curve of degree of infection per unit area of leaf. Growth-rate of host and susceptibility to mildew increased with increasing doses of nitrogen, large increases in infection being shown for small changes in relative growth-rate when the latter was high, and vice versa. When the same dose of nitrogen was given to nitrogen-deficient plants of two sizes, the initially smaller plants became more susceptible to mildew.

A report was given by Miss J. M. Wright and Dr. P. W. Brian (Butterwick Laboratories of Imperial Chemical Industries, Ltd.) of the isolation from some strains of Alternaria solani of a product-referred to as alternaric acid--which had antifungal properties and was also markedly phytotoxic. Dilute solutions (1 p.p.m. or less), when taken up by cut shoots of tomato or potato, produced lesions in stems and leaves which were similar to those formed in natural attack by the fungus. The water-absorbing efficiency of the plant was reduced, with consequent loss of turgor and desiccation. The presence of this substance has been demonstrated in tissues invaded by the fungus. No correlation, however, was obtained between the pathogenicity of various strains and their capacity to produce this acid. Strains of $A$. solani produced a variety of toxic substances, and it would be unsafe at the moment to associate pathogenicity with any one of these to the exclusion of the others.

Finally, Mr. I. A. S. Gibson (Overseas Food Corporation, East Africa) referred to a disease of groundnuts caused by Aspergillus niger. Experiments carried out with five members of the group to which $A$. niger belongs showed that they covered a wide range of pathogenicity and that there was a correlation between this and their acid-producing capacity. The acid primarily concerned was oxalic acid. Growth products from pathogenic strains gave the same effects on host tissue as the appropriate concentrations of oxalic acid. Invasion of the plant by $A$. niger led to collapse and death of the cells in advance of fungal growth, thereby indicating the presence of a toxic precursor to invasion. It appeared, therefore, that oxalic acid played an important part in the establishment of this parasite in the host tissue.

W. BRows

\section{INTERNATIONAL COMMITTEE FOR ELECTROCHEMICAL THERMODYNAMICS AND KINETICS}

\section{MEETING IN BRITAIN}

$T$ THE fourth meeting of the International Committee for Electrochemical Thermodynamics and Kinetics (Comité International de Thermodynamique et de Cinétique Electrochimiques) opened in the Chemistry Department of the Imperial College of Science and Technology, London, on September 10 and continued during September 11-13 in the Department of Metallurgy, University of Cambridge. The aim of the Committee is to provide an international body of those interested in fundamental electrochemistry, especially electrode processes, and to promote contact between these workers and those interested in applied and industrial electrochemistry.

The organization of the London part of the meeting was carried out by Dr. J. O'M. Bockris and that at Cambridge by Dr. T. P. Hoar (vice-president). Among distinguished foreign visitors to the meeting were Profs. G. Charlot (Paris), H. Fischer (Berlin), K. Huber (Berne), E. Lange (Erlangen), R. Piontelli (vice-president, Milan), M. Pourbaix (secretary, Brussels), A. J. Rutgers (Ghent), A. U. Traghardt (Stockholm), G. Valensi (Poitiers), and P. van Rysselberghe (president, Oregon). Among the British electrochemists present in addition to Drs. Hoar and Bockris were Prof. W. F. K. Wynne-Jones and Drs. J. N. Agar and R. Parsons.

In London a lecture was given by Dr. Bockris on "Electrochemical Research at Imperial College", and in Cambridge a lecture by Dr. U. R. Evans entitled "Corrosion Research at Cambridge". About forty papers were presented at the meeting. P. van Rysselberghe treated the theory of polarization in terms of the thermodynamics of irreversible processes and showed how the laws between current and overpotential may be thermodynamically deduced at low current densities. Thermodynamic considerations can be of considerable application in the examination of the complex kinetic processes which occur in, for example, corrosion. The same author also showed how a consideration of the Peltier heats in concentration cells may open up a new approach to the old, but unsolved, problem of absolute electrode potentials. Difficulties preventing progress in the theory of the electric double layer were considered by J. O'M. Bockris. Among these are those connected with the inadequate definition of potential differences at phase boundaries. The independence of the capacity of the negative branch of the electrocapillary curve upon the cations present is still a difficult problem but may be explicable in terms of a model of the solvated ions in the double layer. The importance of attempts to calculate the surface potentials associated with adsorbed dipoles and electron overlap at metal solution interfaces was stressed. 